\title{
Crying and Attachment Style: The Role of Romantic Relationships
}

\author{
Katherine L. Fiori \\ Adelphi University \\ Jessica Buthmann \\ Queens College and the Graduate Center, City University of New York \\ Christy A. Denckla \\ Harvard T. H. Chan School of Public Health
}

Crying is an attachment behavior that functions to elicit support from others (Nelson, 1998); the context in which the crying occurs is important in understanding whether it is adaptive or maladaptive (Hendriks \& Vingerhoets, 2006. However, very little research has examined whether and how attachment style is associated with adult crying, and if this association might vary by an individual's relationship status. Using a sample of 305 first-year college students and a series of hierarchical regressions, we examined the moderating effect of relationship status on the associations between attachment style (measured using the Revised Experiences in Close Relationships Scale; Fraley, Waller, \& Brennan, 2000) and crying frequency and tendency. We found that attachment anxiety was positively associated with both crying frequency and tendency, whereas attachment avoidance was negatively associated with crying tendency. However, we found moderation effects only in the case of attachment avoidance; specifically, we found that attachment avoidance was associated with a lower frequency of crying and tendency to cry only for those individuals involved in romantic relationships. Attachment anxiety, on the other hand, was associated with greater crying frequency and tendency regardless of relationship status. These results demonstrate not only that crying may act as an attachment behavior, but also that the activation or deactivation of this particular attachment behavior may be dependent on the existence of a romantic attachment figure.

Keywords: avoidance, anxiety, crying frequency, crying tendency, college students

\section{Introduction}

Crying in infancy and early childhood has a clear function: to signal distress and secure comfort from caregivers (i.e., food, warmth, etc.) before speech capabilities allow for clearer communication (Zeifman, 2001). So why does crying behavior persist into adulthood, when the ability to communicate needs is well developed? Theory and research suggest that adult crying has evolved to signal the meeting of complex social needs from attachment figures (Bartholomew \& Horowitz, 1991; Nelson, 2005; Vingerhoets, Bylsma, Rottenberg, \& Fögen, 2009). However, in spite of a theoretical understanding of crying as an attachment behavior (Nelson, 2005) and empirical evidence of substantial variations in crying proneness (Vingerhoets, 2013), research linking attachment styles and crying is sparse (Millings, Hepper, Hart, Swift, \& Rowe, 2016). 
The biopsychosocial model of adult crying (Vingerhoets, Cornelius, Van Heck, \& Becht, 2000), used as the theoretical framework for the present study, posits that crying is a function not only of biological and psychosocial traits of the individual (e.g., hormone levels, attachment style), but also of the social context (e.g., the presence of others). For instance, individuals in relationships have been shown to report crying more often than those who are single (Fiori, Consedine, Denckla, \& Vingerhoets, 2013; Vingerhoets \& Van Assen, 2009). No known study to date, however, has examined the intersection of individual and situational factors in predicting crying behaviors. Given that tears may ultimately serve to make individuals more aware of their emotions and of significant events in their lives (Vingerhoets, 2013), and under certain circumstances may also improve mood and foster social bonding (Vingerhoets et al., 2009), it is of both theoretical and clinical utility to understand the intersections of context and individual attributes that predict crying. The purpose of the current study is to build upon the small existing body of research to investigate how attachment style and relationship status interact to predict crying behavior as a means of elucidating the functions of crying in adulthood.

\section{Overview of Attachment Theory}

Beginning in infancy, experiences and interactions with others form the basis for subsequent "internal working models" (Mikulincer \& Shaver, 2007). Internal working models provide a foundation for attitudes toward the self, caregiving, and relationships among adults (Collins, Guichard, Ford, \& Feeney, 2006). These working models are understood to lie along dimensions of attachment anxiety and avoidance, which relate to individuals' views of self and other. Attachment anxiety is predominantly characterized by a negative view of the self (Griffin \& Bartholomew, 1994). Individuals with high levels of this trait may blame themselves for interpersonal problems in relationships rather than blame the relationship partner. Attachment avoidance, on the other hand, is characterized by a negative view of others (Griffin \& Bartholomew, 1994). Individuals with high levels of avoidance may prefer to be emotionally independent rather than depend on others for emotional support. Whereas avoidance is characterized by the suppression of emotions (Gillath, Bunge, Shaver, Wendelken, \& Mikulincer, 2005), attachment anxiety is built around acting out in order for needs to be met (Mikulincer \& Shaver, 2007).

Adult attachment "styles" can be categorized based on these aforementioned dimensions of attachment avoidance and anxiety. For example, individuals with a dismissive attachment style exhibit high avoidance and low anxiety and tend to engage in deactivating strategies (such as extreme self-reliance and avoiding physical closeness) that create distance between themselves and others (Collins et al., 2006). Preoccupied attachment, on the other hand, is characterized by low avoidance, high anxiety, and a tendency to engage in hyperactivating strategies (such as intense distress and excessively seeking reassurance) to have attachment needs met, which may appear intrusive and demanding to an attachment figure (such as a romantic partner; Collins et al., 2006). These behaviors mirror the strategies employed by infants with high attachment avoidance or anxiety. For example, upon separation from an attachment figure, anxious attachment in both children and adults may be characterized by crying or sadness, whereas avoidant attachment may be characterized by relative indifference (Ainsworth \& Bell, 1970; Collins et al., 2006). Next, research more explicitly examining the links between attachment styles/dimensions and crying is presented. 


\section{Attachment, Relationships, and Crying}

Crying in infants and young children is understood as a signal that some form of caregiving is required to address discomfort or distress experienced by the child. As already described (Ainsworth \& Bell, 1970), those with high levels of attachment anxiety tend to engage in crying behavior more often than other children in the same scenario. Although research suggests that adults with anxious internal working models may employ similar hyperactivating strategies with attachment figures to have their needs met (Collins et al., 2006), it is still unclear what individual and contextual factors may contribute to engagement in these strategies. The current body of research provides some clues, however. For example, Hendriks and Vingerhoets (2006) found that after viewing pictures of other adults crying, participants felt more inclined to provide emotional support and less inclined to be hostile or aggressive, suggesting that the act or appearance of crying elicits caregiving tendencies, regardless of the age of the crier.

In line with the idea that adult attachment styles may be linked to crying behaviors, Bartholomew and Horowitz (1991) found attachment style differences in crying behavior among undergraduate students aged 18-22. Specifically, they found that those with a dismissive attachment style reported crying the least frequently, whereas those with a preoccupied style reported crying the most frequently, with the crying frequency of those with secure attachment between the two groups. Similarly, Laan, Van Assen, and Vingerhoets (2012) found that dismissive adults cried the least in general and in response to music, whereas preoccupied adults cried more intensely and reported more negative emotions while crying. Consistent with these findings, but using a dimensional measure of attachment (as in the present study), Millings et al. (2016) found positive links between attachment anxiety and crying proneness and negative links between attachment avoidance and crying proneness in a large sample of adults ranging in age from 18 to 81 . In a related study of undergraduates, a maladaptive dependency on others predicted increased crying proneness (Fiori et al., 2013). Interestingly, the same study found that social support and crying proneness were more closely related for individuals high on measures of maladaptive dependency, implying that highly dependent individuals may be particularly adept at using crying behaviors to garner social support.

Indeed, research indicates that the ways in which individuals use and experience crying are different depending on individuals' attachment styles (Drenger, Mikulincer, \& Berant, 2016; Millings et al., 2016). For example, in a recent study of Israeli adults, Drenger and colleagues (2016) found that whereas attachment anxiety was associated with an exaggerated and emotionally ambivalent crying experience, individuals high on attachment avoidance experienced crying as more restricted and negative. Millings and colleagues (2016) found that individuals high on attachment anxiety had more positive attitudes towards crying (e.g., reporting crying as being healthy) but also viewed crying as less controllable, whereas those high on avoidance held more negative attitudes towards crying (e.g., reporting that crying is not healthy) but also viewed crying as more controllable. In turn, these attitudes at least partially explained the positive and negative associations, respectively, between attachment anxiety and avoidance and crying recency, duration, and intensity.

A clear pattern emerges from this body of research indicating that individuals who are more socially reliant on others to meet their interpersonal needs cry at higher rates and for different reasons than those who are less reliant on others. Less understood is how these varying interpersonal needs may interact with the salience of an actual attachment figure (e.g., being romantically involved) in predicting crying. Studies have consistently found that individuals in relationships cry more often than those who are single (Fiori et al., 2013; Vingerhoets \& Van Assen, 2009). Vingerhoets (2013) has speculated that more frequent crying for those in relationships could be due to an increase in 
conflicts and disagreements with others (e.g., due to interference in responsibilities and routines), increased stress involved in being in a romantic relationship (particularly among adolescents), and/or a lowered threshold for crying due to the availability of an attachment figure. Indeed, if crying is viewed as an attachment behavior, it follows that crying may serve to elicit caregiving from the attachment figure, and therefore would be observed at a higher rate in those with relationship partners.

As mentioned, however, it remains unknown whether the attachment style variations seen for crying differ depending on whether the individual is in a serious romantic relationship. The biopsychosocial model of crying (Vingerhoets et al., 2000) posits that biological (e.g., sex), psychosocial (e.g., attachment style), and situational factors (e.g., romantic partner) all contribute to determine whether an individual will cry in a given situation. Vingerhoets and colleagues conceptualize these factors as "moderators," in the sense that they may alter any number of antecedents and/or pathways leading to crying (e.g., the individual's emotional state, or the pathway between emotional state and crying, etc.). Although pieces of this model have been supported by prior research, still unknown are the ways in which these factors may interact with each other in predicting crying. However, some prior research implies that the attachment-crying link may be stronger among those in relationships (Fiori et al., 2013). Understanding whether an attachment-related propensity for crying varies depending on relationship status could lend insight into both our understanding of the functions of crying as well as individual differences in emotion expression more broadly.

\section{The Present Study}

Using Vingerhoets et al.'s (2000) biopsychosocial model of crying as the theoretical framework, in the present study, we examined whether and how attachment style (a psychosocial factor) and relationship status (a situational factor) might interact to predict crying behavior. In order to encompass the complexities of crying behavior, we surveyed crying frequency in the past year, crying frequency in the past 4 weeks, and overall crying tendency. Prior research suggests that frequency and tendency differ in that the former is dictated more by context, whereas the latter is largely determined by personality traits (Groen-Blokhuis, Middeldorp, van Beijsterveldt, \& Boomsma, 2011; Denckla, Fiori, \& Vingerhoets, 2014).

We hypothesized that the attachment dimension of anxiety would positively predict all measures of crying, whereas dimensional attachment avoidance would negatively predict these measures. Also, in accordance with prior research (Fiori et al., 2013; Vingerhoets \& Van Assen, 2009), we expected that being in a romantic relationship would be associated with greater crying frequency and tendency than being single. Furthermore, we hypothesized that relationship status would moderate the associations between attachment and crying. Specifically, we predicted that positive associations between anxiety and crying (in particular, crying frequency), would be amplified for those in relationships (because crying proneness may be less dependent on the situational factor of romantic involvement).

\section{Method}

\section{Participants}

The data for the present study come from the first wave of a longitudinal study, the original purpose of which was to examine changes in the social networks of students transitioning to college. At this first wave, a paper-and-pencil survey was administered to first-year college students at a small private university in the northeast of the United States. The response rate was $39 \%(N=305)$. The 
majority $(N=256,84 \%)$ were female and Caucasian (63\% Caucasian, $12 \%$ African American, 10\% Asian, 7\% Hispanic, and 7\% other). The mean age was 18.06 years $(S D=1.89)$. Approximately half lived on campus (46\%), whereas the other half lived at home with their parents $(54 \%)$.

\section{Procedure}

The survey was handed out in paper-and-pencil format in freshman seminars and advertised via email at the beginning of the fall semester. Every person who received the survey was told that their participation was voluntary and their answers would be kept anonymous. Informed consent was obtained from every student who chose to participate. Each participant was entered into a drawing for a $\$ 25$ or $\$ 50$ Amazon gift card. All procedures were approved by Adelphi University's Institutional Review Board (Approval \#040110).

\section{Measures}

\section{Relationship Status}

Participants were asked to indicate their relationship status by responding on a 3-point scale $(0=n o t$ in a relationship, $1=$ in a relationship but not living together, and $2=i n$ a relationship and living together). We recoded "in a relationship but not living together" and "in a relationship and living together" into one group because only three participants fell into the latter category.

\section{Attachment Style}

Participants' attachment style was measured using the Experiences in Close Relationships-Revised Scale (Fraley, Waller, \& Brennan, 2000). This scale contains 36 self-report items that are responded to on a 7-point scale from 1 (strongly disagree) to 7 (strongly agree). Sibley, Fischer, and Liu (2005) demonstrated the strong convergent and discriminant validity of this measure with other temperament instrumentation. Two subscales measure attachment anxiety and attachment avoidance. The 18-item Anxiety subscale contains items such as "I worry that others won't care about me as much as I care about them." This subscale was highly reliable within the present sample (Cronbach's $\alpha=.89$ ). The 18-item Avoidance subscale included items such as "I don't feel comfortable opening up to others," and was also highly reliable (Cronbach's a $=.83$ ).

\section{Crying}

Crying behavior was measured in three ways. Crying frequency in the past year was assessed on a 7 point scale from 1 (about once a year or less) to 7 (nearly every day) in response to the question, "Thinking over the past year or so, about how frequently do you cry (excluding crying because of books, movies, television shows, etc.)?" Crying in the last 4 weeks was assessed via the open-ended question "Can you estimate how often you have cried in the last 4 weeks?" Lastly, crying tendency was assessed on a 10-point scale from 1 (I hardly ever cry) to 10 (I can very easily cry) in response to the question, "How would you rate your general tendency to cry?" These measures were all adapted from the Adult Crying Inventory (Vingerhoets \& Becht, 1996).

\section{Statistical Approach}

We utilized a dimensional approach to measuring attachment avoidance and anxiety rather than a categorical approach in order to maximize variability. For each crying outcome (crying frequency in the past year, crying frequency in the last 4 weeks, and crying proneness), we performed a two-step hierarchical linear regression with gender, relationship status, and the two attachment dimensions (anxiety and avoidance) entered at Step 1, and interaction terms between relationship status and 
each of the attachment dimensions entered at Step 2. Gender was covaried in all analyses given the well-established gender differences in crying (Vingerhoets \& Scheirs, 2000).

\section{Results}

\section{Crying Frequency Over the Past Year}

As shown in Step 1 of Table 1, being female $(\beta=.40, p<.001)$ was positively associated with crying frequency in the past year. Consistent with our hypotheses, being in a relationship $(\beta=.21, p<.01)$ and attachment anxiety $(\beta=.27, p<.001)$ also positively predicted crying frequency in the past year. However, contrary to our hypotheses, there was no significant association between attachment avoidance and crying frequency. Furthermore, as seen in Step 2, there was no significant interaction between anxiety and relationships status. Instead, the interaction term between attachment avoidance and relationship status was significant $(\beta=-.18, p<.01)$. As shown in Figure 1 , individuals who were in a relationship and low on attachment avoidance (defined as below the median) reported crying more frequently over the past year $(n=66, M=4.02, S D=1.53)$ than those who were in a relationship and high on avoidance $(n=36, M=3.42, S D=1.40)$; this association trended towards significance, $t(100)=1.94, p=.055$. In contrast, for those not in relationships, the association was reversed, with individuals low on attachment avoidance crying significantly less frequently $(n=71, M=2.79, S D=1.43)$ than those high on attachment avoidance $(n=99, M=3.28$, $S D=1.53), t(168)=-2.13, p<.05$.

Table 1. Attachment and Relationship Status Predicting Crying Frequency in the Past Year

\begin{tabular}{lcccccc} 
& \multicolumn{3}{c}{ Step 1} & \multicolumn{3}{c}{ Step 2} \\
\cline { 2 - 7 } Variables & $B$ & $S E B$ & $\beta$ & $B$ & $S E B$ & $\beta$ \\
\hline Female & 1.69 & .22 & $.40^{* * *}$ & 1.69 & .22 & $.38^{* * *}$ \\
Attachment anxiety & .38 & .08 & $.27^{* * *}$ & .34 & .10 & $.24^{* *}$ \\
Attachment avoidance & -.14 & .09 & -.09 & .03 & .11 & .02 \\
Relationship status & .67 & .17 & $.21^{* * *}$ & .59 & .17 & $.19^{* *}$ \\
Anxiety $\times$ Relationship & & & & .07 & .16 & .03 \\
Avoidance $\times$ Relationship & & & & -.56 & .20 & $-.18^{* *}$ \\
\hline$* * p<.01 * * * p<.001$. & & & & & &
\end{tabular}




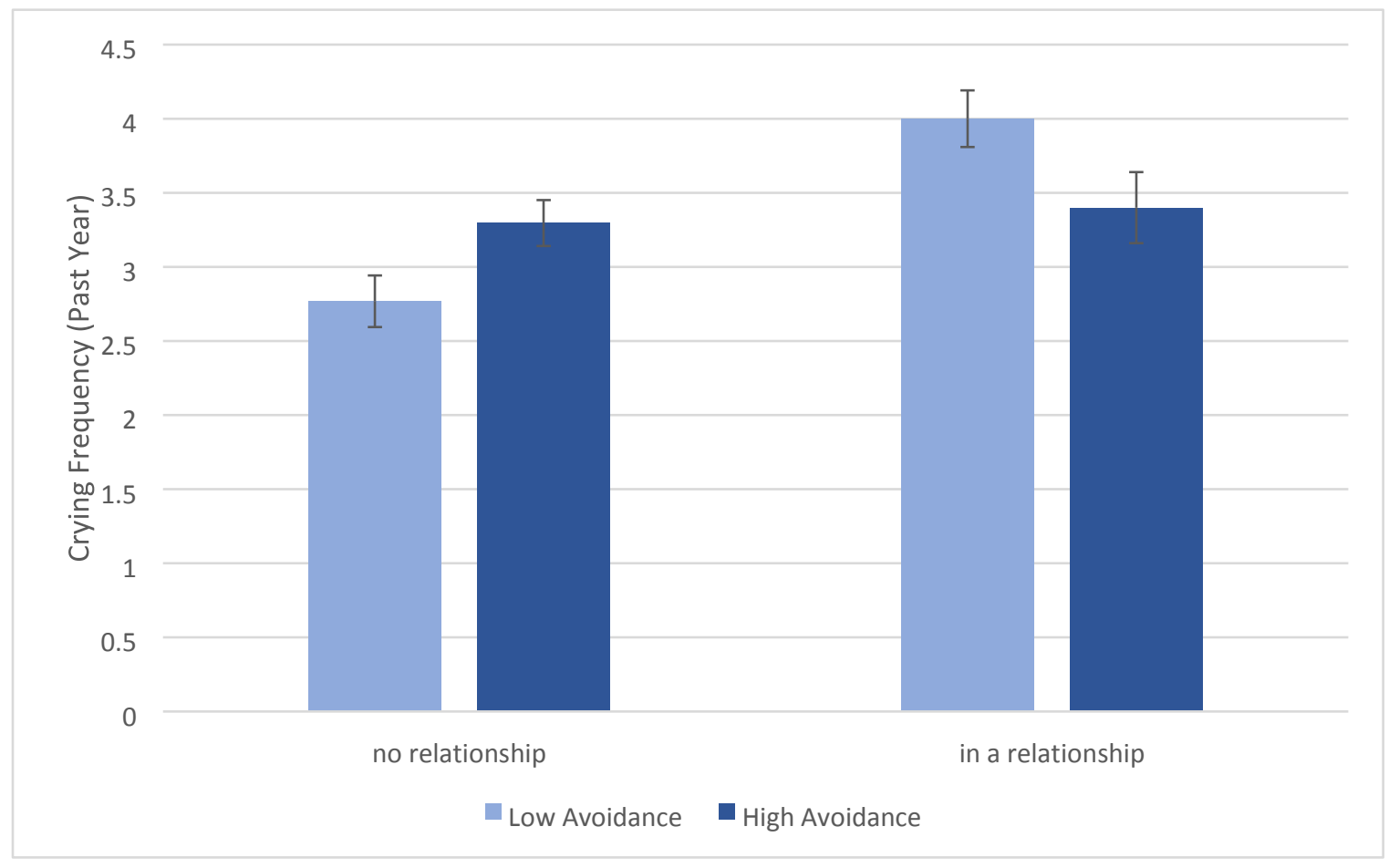

Figure 1. Attachment Avoidance (Low = Below the Median; High = Above the Median) and Relationship Status Interact to Predict Crying Frequency Over the Past Year

\section{Crying Frequency Over the Past 4 Weeks}

As shown in Step 1 of Table 2 , being female $(\beta=.15, p<.05)$ positively predicted crying frequency over the past 4 weeks. Consistent with our hypotheses, being in a relationship $(\beta=.14, p<.05)$ and attachment anxiety $(\beta=.17, p<.01)$ also positively predicted crying frequency, with a trend for avoidance negatively predicting crying frequency $(\beta=-.11, p=.095)$. However, as seen in Step 2 and contrary to our hypotheses, the interaction between anxiety and relationship status was not significant in predicting crying frequency. Interestingly, however, and consistent with the findings for crying frequency over the past year, the interaction term between attachment avoidance and relationship status predicting crying over the past 4 weeks was significant $(\beta=-.20, p<.01)$. As shown in Figure 2, individuals who were in a relationship and low on attachment avoidance (defined as below the median) reported crying significantly more frequently over the past 4 weeks $(n=67, M$ $=6.27, S E=.98)$ than those who were in a relationship and high on avoidance $(n=35, M=5.04, S E$ $=.85), t(100)=2.16, p<.05$. In contrast, for those not in relationships, the association was reversed. Individuals low on attachment avoidance reported crying less frequently in the past 4 weeks $(n=70$, $M=2.74, S E=.35)$ than those high on attachment avoidance $(n=101, M=3.94, S E=.57)$. These differences also trended towards significance according to a $t$ test, $t(169)=-1.80, p=.074$. 
Table 2. Attachment and Relationship Status Predicting Crying Frequency in the Past 4 Weeks

\begin{tabular}{lcccccc} 
& \multicolumn{3}{c}{ Step 1 } & \multicolumn{3}{c}{ Step 2} \\
\cline { 2 - 7 } Variables & $B$ & $S E B$ & $\beta$ & $B$ & $S E B$ & $\beta$ \\
\hline Female & 2.43 & .93 & $.15^{*}$ & 2.39 & .93 & $.15^{*}$ \\
Attachment anxiety & .91 & .33 & $.17^{* *}$ & .64 & .43 & .12 \\
Attachment avoidance & -.67 & .40 & $-.11^{\dagger}$ & .04 & .47 & .01 \\
Relationship status & 1.74 & .72 & $.14^{*}$ & 1.46 & .73 & $.12^{*}$ \\
Anxiety $\times$ Relationship & & & & .62 & .67 & .07 \\
Avoidance $\times$ Relationship & & & & -2.31 & .86 & $-.20^{* *}$ \\
\hline
\end{tabular}

${ }^{\dagger} p<.10 .{ }^{*} p<.05 .{ }^{* *} p<.01$.

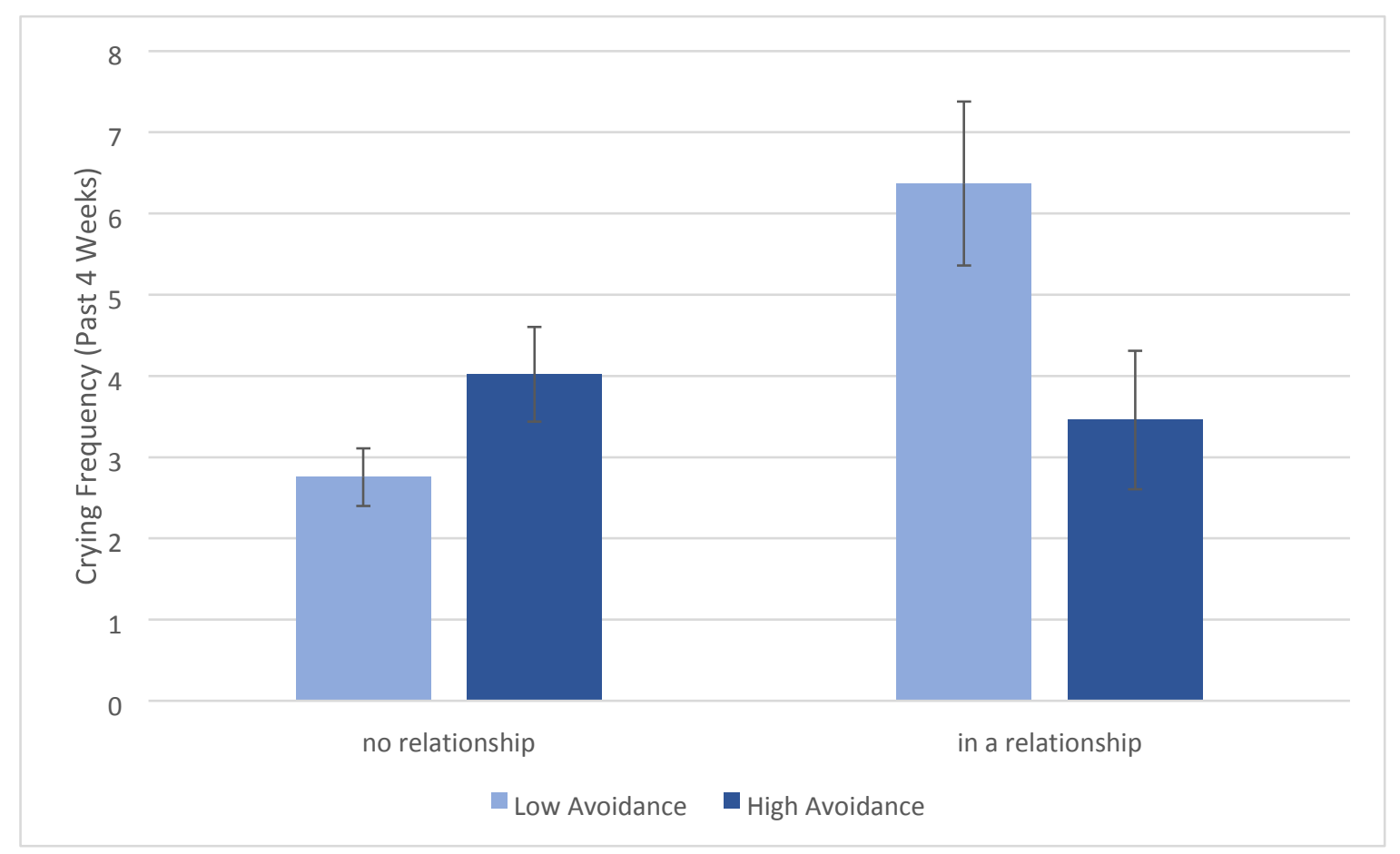

Figure 2. Attachment Avoidance (Low = Below the Median; High = Above the Median) and Relationship Status Interact to Predict Crying Frequency Over the Past 4 Weeks 


\section{Crying Tendency}

As shown in Step 1 of Table 3, being female $(\beta=.45, p<.001)$ was positively associated with crying tendency. In addition, as predicted, being in a relationship $(\beta=.14, p<.01)$ and anxious attachment $(\beta=.28, p<.001)$ both positively predicted crying tendency. Also as hypothesized, attachment avoidance negatively predicted crying tendency $(\beta=-.19, p=.047)$. Finally, as seen in Step 2 , although the interaction between attachment anxiety and relationship status was not significant, the interaction between attachment avoidance and relationship status was significant at the level of a trend $(\beta=-.11, p=.077)$. The pattern of findings was similar to those for both crying frequency in the past year and crying frequency over the past 4 weeks. Specifically, Figure 3 shows that those who are low on attachment avoidance and in a relationship are more prone to cry than those who are high on avoidance and in a relationship, whereas there are no differences in crying tendency for those not in relationships.

Table 3. Attachment and Relationship Status Predicting Crying Tendency

\begin{tabular}{lcccccc}
\hline & \multicolumn{3}{c}{ Step 1 } & \multicolumn{3}{c}{ Step 2 } \\
\cline { 2 - 7 } Variables & $B$ & $S E B$ & $\beta$ & $B$ & $S E B$ & $\beta$ \\
\hline Female & 3.41 & .37 & $.45^{* * *}$ & 3.41 & .37 & $.46^{* * *}$ \\
Attachment anxiety & .71 & .13 & $.28^{* * *}$ & .70 & .17 & $.28^{* * *}$ \\
Attachment avoidance & -.56 & .16 & $-.19^{* * *}$ & -.39 & .19 & $-.13^{*}$ \\
Relationship status & .79 & .29 & $.14^{* *}$ & .70 & .29 & $.12^{*}$ \\
Anxiety $\times$ Relationship & & & & .01 & .27 & .00 \\
Avoidance $\times$ Relationship & & & & -.61 & .34 & $-.11^{\dagger}$ \\
\hline
\end{tabular}

${ }^{\dagger} p<.10 .{ }^{*} p<.05 .{ }^{* *} p<.01 .{ }^{* * *} p<.001$. 


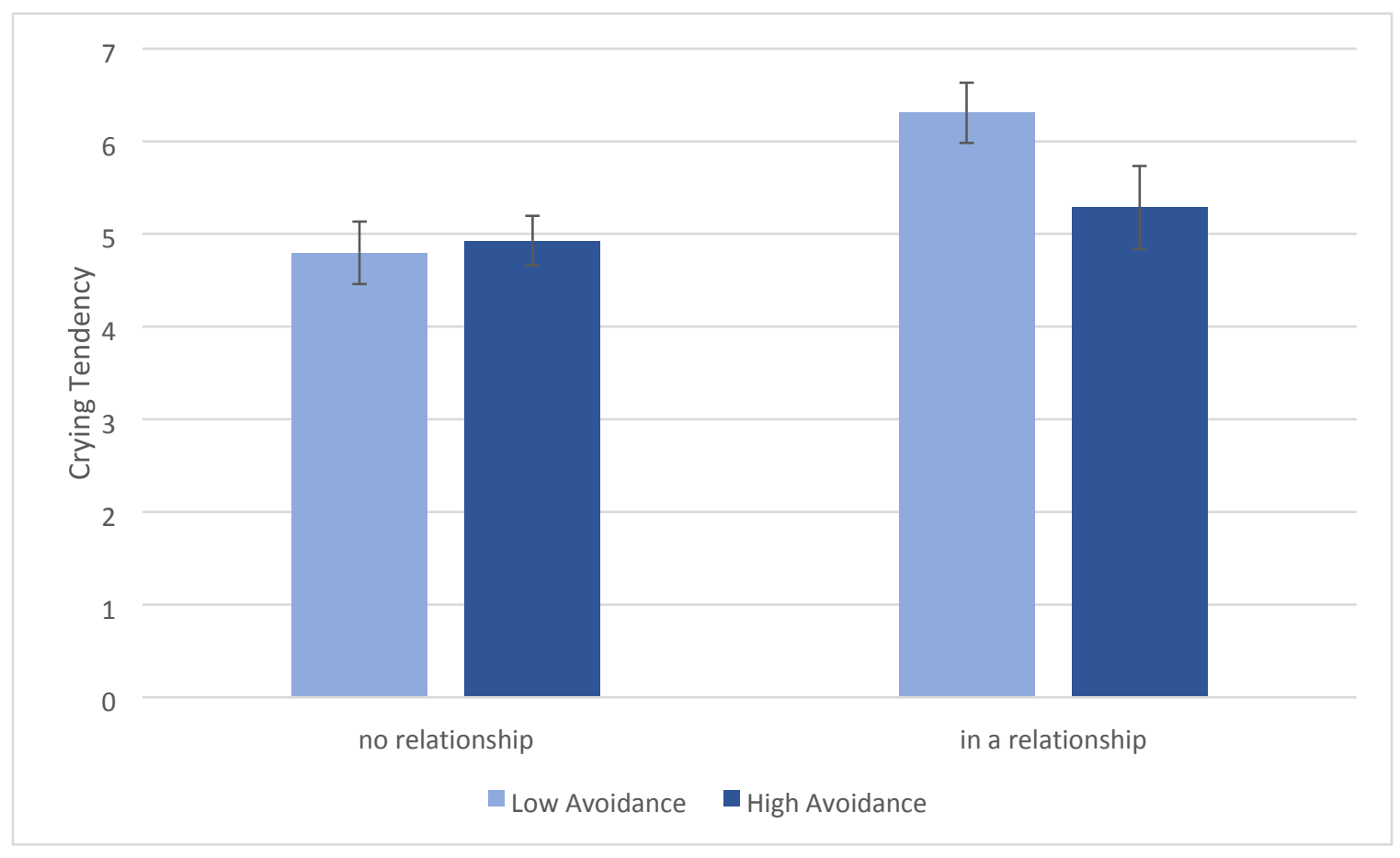

Figure 3. Attachment Avoidance (Low = Below the Median; High = Above the Median) and Relationship Status Interact to Predict Crying Tendency

\section{Discussion}

Crying is a universal attachment behavior whose antecedents and consequences are quite varied, in part due to large individual differences in the proneness to cry (Vingerhoets, 2013). Attachment styles are just one of the individual differences that appear to be associated with both crying frequency and intensity (e.g., Millings et al., 2016). In the present study, we examined the moderating role of the presence of an attachment figure (such as a romantic partner) on the association between attachment styles and crying in a sample of college students. We predicted that attachment anxiety and relationship status would interact in predicting crying frequency and tendency, given evidence that highly dependent individuals may utilize crying to garner social support (Fiori et al., 2013). That is, we expected highly anxious individuals in relationships to cry more frequently than those not in relationships.

In general, we found the expected associations between attachment styles and crying frequency and tendency (e.g., positive associations between anxious attachment and crying frequency/tendency, and a negative association between avoidant attachment and crying tendency). These findings are consistent with other research showing similar links between attachment styles and crying behaviors (e.g., Bartholomew \& Horowitz, 1991; Millings at al., 2016). Our findings are also consistent with the idea that highly anxious individuals utilize a hyperactivating attachment strategy that includes a low threshold for crying (Mikulincer \& Shaver, 2007; Nelson, 2008), whereas highly avoidant individuals respond to attachment-related threats with deactivating strategies. As predicted, we also found that being in a romantic relationship was associated with higher levels of crying frequency and tendency, again consistent with previous research (e.g., Fiori et al., 2013; 
Vingerhoets \& Van Assen, 2009) and with the idea that the availability of an attachment figure may also reduce the threshold for crying (Vingerhoets, 2013).

Unexpectedly, however, it was attachment avoidance, rather than attachment anxiety, that moderated the association between romantic relationship status and crying frequency/tendency (while controlling for levels of anxiety). Specifically, individuals high on attachment avoidance were less likely to cry when in a relationship compared to those low on attachment avoidance, whereas they were more likely to cry when not in a relationship. Although this interaction was significant for both crying frequency over the past year and crying frequency over the past 4 weeks, the effect was less pronounced for crying tendency, where we found only a trend. This is likely due to the fact that the tendency to cry may be a more stable personality characteristic that is less dependent on the situational factor of romantic involvement (Groen-Blokhuis et al., 2011; Denckla et al., 2014).

So why did attachment avoidance, rather than attachment anxiety, interact with romantic relationship status in predicting crying behaviors? Recent research from Drenger and colleagues (2016) examining the subjective experiences of crying can offer some insight. In their study of Israeli adults, they found that highly avoidant individuals were less likely to report crying in the presence of close others than less avoidant individuals. Furthermore, whereas the experience of crying for anxiously attached individuals was rather ambivalent (with a mix of negative and positive feelings), attachment avoidance was associated primarily with feelings of discomfort, wishes for restraint, and lower wishes for intimacy. Thus, individuals high on avoidance may experience crying as a negative event, particularly when in a relationship, because such displays of emotion may cause unpleasant feelings of vulnerability and discomfort within this context. Furthermore, because highly avoidant individuals tend to view crying as controllable (Millings et al., 2016), it may be that avoidant adults consciously refrain from crying as a way to help them maximize feelings of intimacy for a significant other.

In sum, in line with the biopsychosocial model of crying (Vingerhoets et al., 2000), our results indicate that the association between a psychosocial factor (attachment style) and crying behavior is moderated by a situational factor (relationship status). More specifically, whereas anxious attachment appears to be associated with crying frequency and tendency regardless of relationship status, the association of attachment avoidance and crying seems more sensitive to context. That is, individuals who are low on attachment avoidance (above and beyond levels of anxiety) report crying more when in romantic relationships, perhaps in part as a way to garner emotional support from their partner. On the other hand, individuals high on attachment avoidance may be disinclined to seek fulfillment of attachment needs through such methods, particularly from significant others (Bartholomew \& Horowitz, 1991; Collins et al., 2006; Millings et al., 2016).

\section{Limitations and Future Directions}

These findings should be interpreted in light of several limitations of the study. First, the study is cross-sectional and correlational. Thus, the direction of effects is unclear. For example, although we assume that avoidantly attached individuals in relationships are (consciously or subconsciously) limiting or inhibiting crying as a way to maintain some level of intimacy with their significant other, it is of course possible that individuals who are high on both attachment avoidance and crying tendency are less likely to end up in (or stay in) relationships in the first place. Although in general tears appear to induce empathy and positive feelings in others, the characteristics of the crying person, as well as of the crying itself, seem to play an important part in the affective and behavioral responses of the observer (Vingerhoets, 2013). It is possible that "frequent criers" may be seen as less 
attractive romantic partners (and/or potential romantic partners), particularly if they also display behaviors typical of those high on attachment avoidance as well (e.g., excessive self-reliance).

Second, all our study participants were undergraduate college students, and the majority of the participants (85\%) were female, limiting the generalizability of our findings. Indeed, research shows that females are significantly more prone to cry than are males (Peter, Vingerhoets, \& van Heck, 2001). However, we controlled for gender in all our analyses, and there were no significant three-way interactions between relationship status, attachment style, and gender. In fact, in follow-up tests, the associations among relationship status, attachment style, and crying behaviors largely retained the same patterns across both genders. Regardless, future research using larger, more diverse samples of participants (e.g., married vs. single adult males and females) is needed to better clarify the nature of these associations within a broader population.

Finally, the retrospective aspects of the self-report crying measures make them prone to reliability problems. However, the fact that our findings were similar across all three measures of crying (frequency and tendency) provides some support for their reliability, because, presumably, crying tendency would be less affected by self-reporting errors. Similarly, it is important to note that we assessed only frequency and tendency of crying; we did not distinguish among different types of crying, nor did we ask individuals about their motivations for crying. According to an attachment perspective (Nelson, 2005), there are three types of crying, even among adults: "protest crying," characterized by loud, persistent screams designed to immediately change a distressful situation; "sad crying," a quieter cry often following protest crying designed to elicit emotional support; and finally, "detached crying," typically characterized by an absence of tears that may occur under only extreme circumstances, such as severe traumatic experiences. It is possible, and perhaps likely, that the crying about which individuals were reporting frequency also varied in type and purpose. For example, perhaps highly avoidant individuals are more likely to experience detached crying, which they may or may not include in reports of actual crying episodes, whereas highly anxious individuals may be more likely to experience and report protest crying. Future research is needed to develop accurate assessment tools for these different types of crying, and to determine whether individuals with varying attachment styles also experience varying types of and motivations for crying (e.g., garnering immediate attention vs. eliciting emotional support), both in and outside of romantic relationships. Relatedly, we did not ask whether crying occurred privately or in front of the romantic partner. Although individuals are thought to invoke thoughts of attachment figures even when crying alone (Fridlund, 1994), it will be important in future research to uncover more details about specific crying episodes.

\section{Conclusions}

Crying is an incredibly complex, understudied phenomenon that is clearly tied to our evolutionary history as social creatures (Vingerhoets, 2013). In spite of the universal nature of infant crying, however, there are vast individual differences in adult crying tendencies that appear driven not just by psychosocial factors, but also by situational context (Vingerhoets et al., 2000). The present study offers evidence of the important role of such contexts in understanding the association between a key psychosocial factor whose roots lie in infancy (i.e., attachment style) and the outward emotional expression of crying among adults. Specifically, our findings indicate that attachment avoidance, which is typically characterized by the suppression of emotions (Gillath et al., 2005) and has been negatively linked to crying proneness (Millings et al., 2016), may not always be associated with reduced emotional expression. That is, it seems that avoidance may only be associated with lower crying frequency and tendency for individuals involved in romantic relationships. Although these 
results have implications for our understanding of crying as an attachment behavior, future research is needed to clarify whether attachment styles and presence of a romantic partner also interact to shape why individuals cry and in what type of crying they engage.

\section{References}

Ainsworth, M. D. S., \& Bell, S. M. (1970). Attachment, exploration, and separation: Illustrated by the behavior of one-year-olds in a strange situation. Child Development, 41, 49-67. doi:10.2307/1127388

Bartholomew, K., \& Horowitz, L. M. (1991). Attachment styles among young adults: A test of a fourcategory model. Journal of Personality and Social Psychology, 61, 226-244. doi:10.1037/00223514.61.2.226

Collins, N. L., Guichard, A. C., Ford, M. B., \& Feeney, B. C. (2006). Responding to need in intimate relationships: Normative processes and individual differences. In M. Mikulincer \& G. S. Goodman (Eds.), Dynamics of romantic love: Attachment, caregiving, and sex (pp. 149-189). New York, NY: Guilford Press.

Denckla, C. A., Fiori, K. L., \& Vingerhoets, A. J. (2014). Development of the crying proneness scale: Associations among crying proneness, empathy, attachment, and age. Journal of Personality Assessment, 96, 619-631. doi:10.1080/00223891.2014.899498

Drenger, M., Mikulincer, M., \& Berant, E. (2016). Attachment orientations and adult crying. Psychoanalytic Psychology. Advance online publication. doi:10.1037/pap0000096

Fiori, K. L., Consedine, N. S., Denckla, C. A., \& Vingerhoets, A. J. J. M. (2013). Crying in context: Understanding associations with interpersonal dependency and social support. Interpersona, 7, 44. doi:10.5964/ijpr.v7i1.109

Fraley, R. C., Waller, N. G., \& Brennan, K. A. (2000). An item response theory analysis of self-report measures of adult attachment. Journal of Personality and Social Psychology, 78, 350-365. doi:10.1037/0022-3514.78.2.350

Fridlund, A. (1994). Human facial expression: An evolutionary view. San Diego, CA: Academic Press.

Gillath, O., Bunge, S. A., Shaver, P. R., Wendelken, C., \& Mikulincer, M. (2005). Attachment style differences in the ability to suppress negative thoughts: exploring the neural correlates. Neuroimage, 28, 835-847. doi:10.1080/02699930500450218

Griffin, D. W., \& Bartholomew, K. (1994). Models of the self and other: Fundamental dimensions underlying measures of adult attachment. Journal of Personality and Social Psychology, 67, 430-445. doi:10.1037/0022-3514.67.3.430

Groen-Blokhuis, M. M., Middeldorp, C. M., van Beijsterveldt, C. E., \& Boomsma, D. I. (2011). Crying without a cause and being easily upset in two-year-olds: heritability and predictive power of behavioral problems. Twin Research and Human Genetics, 14, 393-400. doi:10.1375/twin.14.5.393

Hendriks, M. C., \& Vingerhoets, A. J. (2006). Social messages of crying faces: Their influence on anticipated person perception, emotions and behavioural responses. Cognition and Emotion, 20, 878-886. doi:10.1080/02699930500450218

Laan, A. J., Van Assen, M. A., \& Vingerhoets, A. J. (2012). Individual differences in adult crying: The role of attachment styles. Social Behavior and Personality: An International Journal, 40, 453-471. doi:10.2224/sbp.2012.40.3.453 
Mikulincer, M., \& Shaver, P. R. (2007). Attachment in adulthood: Structure, dynamics, and change. New York, NY: Guilford Press.

Millings, A., Hepper, E. G., Hart, C. M., Swift, L., \& Rowe, A. C. (2016). Holding back the tears: Individual differences in adult crying proneness reflect attachment orientation and attitudes to crying. Frontiers in Psychology, 7. doi:10.3389/fpsyg.2016.01003

Nelson, J. K. (2005). Seeing through tears: Crying and attachment. New York, NY: Psychology Press.

Nelson, J. K. (2008). Crying in psychotherapy: Its meaning, assessment, and management based on attachment theory. In A. J. J. M. Vingerhoets, I. Nyklíček, \& J. Denollet (Eds.), Emotion regulation: Conceptual and clinical issues (pp. 202-214). New York, NY: Springer. doi:10.1007/978-0-387-29986-0_13

Peter, M., Vingerhoets, A. J., \& Van Heck, G. L. (2001). Personality, gender, and crying. European Journal of Personality, 15, 19-28. doi:10.1002/per.386

Sibley, C. G., Fischer, R., \& Liu, J. H. (2005). Reliability and validity of the revised experiences in close relationships (ECR-R) self-report measure of adult romantic attachment. Personality and Social Psychology Bulletin, 31, 1524-1536. doi:10.1177/0146167205276865

Vingerhoets, A. (2013). Why only humans weep: Unraveling the mysteries of tears. Oxford, United Kingdom: Oxford University Press.

Vingerhoets, A. J., Cornelius, R. R., Van Heck, G. L., \& Becht, M. C. (2000). Adult crying: A model and review of the literature. Review of General Psychology, 4, 354-377. doi:10.1037/10892680.4.4.354

Vingerhoets, A. J., \& van Assen, M. A. (2009, August). Love and tears. Poster presented at the Annual Meeting of the International Society for Research on Emotion, Leuven, Belgium.

Vingerhoets, A. J. J. M., \& Becht, M. C. (1996). Adult Crying Inventory (ACI). Unpublished manuscript, Department of Psychology, Tilburg University, The Netherlands.

Vingerhoets, A. J. J. M., Bylsma, L., \& Rottenberg, J., \& Fögen, T. (2009). Crying: A biopsychosocial phenomenon. In T. Fögen (Ed.), Tears in the Graeco-Roman world (pp. 439-475). Berlin, Germany: de Gruyter. doi:10.1515/9783110214024.439

Vingerhoets, A. J. J. M., \& Scheirs, J. (2000). Sex differences in crying: Empirical findings and possible explanations. Gender and Emotion: Social Psychological Perspectives, 2, 143-165.

Zeifman, D. M. (2001). An ethological analysis of human infant crying: answering Tinbergen's four questions. Developmental Psychobiology, 39, 265-285.

The Journal of Social, Behavioral, and Health Sciences is an open-access, peer-reviewed, online interdisciplinary journal focusing on research findings that address contemporary national and international issues. Its objectives are to (a) encourage dialogue between scholars and practitioners in the social, behavioral, and health sciences that fosters the integration of research with practice; (b) promote innovative models of interdisciplinary collaboration among the social, behavioral, and health sciences that address complex social problems; and (c) inform the relationship between practice and research in the social, behavioral, and health sciences.

Walden University Publishing: http://www.publishing.waldenu.edu 